\title{
The human hypothalamus in aging and dementia
}

\author{
D. F. Swaab
}

Recent research into the human hypothalamus has revealed a number of morphological and functional changes during the process of aging and in Alzheimer's disease, the most common cause of dementia. There is a causal relationship, at least partly, between these alterations and the well-known changes in functions observed during, e.g. sleep disturbances, restlessness, diminished sexual activity, changes in eating behavior and metabolism, activation of the adrenal system, mood changes and menopausal flushes. Quite a few of the alterations observed in the hypothalamic nuclei during aging and in Alzheimer's disease are caused by changes outside this brain structure: the visual system in the case of the suprachiasmatic nucleus, kidney changes in the case of the supraoptic and paraventricular nucleus and changes in sex hormone levels in the case of the arcuate nucleus. This offers the exciting possibility of influencing the aging process of this part of the brain by correcting the neural and hormonal input of the hypothalamus.

\section{Suprachiasmatic nucleus}

The suprachiasmatic nucleus $(\mathrm{SCN})$ is a small structure $\left(0.25 \mathrm{~mm}^{3}\right)$ that is considered to be the major circadian pacemaker of the mammalian brain, coordinating hormonal and behavioral circadian rhythms [46]. In conventionally thionine-stained sections the human SCN cannot be recognized with certainty and therefore immunocytochemical labelling of the nucleus is necessary [61]. The shape of the human SCN is sexually dimorphic, i.e. more elongated in women and more spherical in men, but the vasopressin cell number and volume are similar in both sexes [58]. Neurons that are immunoreactive for vasopressin, vasoactive intestinal polypeptide (VIP), neuropeptide-Y and neurotensin are present in the SCN in a particular anatomical organization $[36,38]$. Typical for the human SCN, as compared to monkeys and other animals, are (1) the very large population of neurotensin cells and (2) the large population of NPY neurons obscuring a geneticulo-hypothalamic tract - if such a tract is present in the human brain at all [38]. Recent observations have revealed a marked seasonal variation in the volume and cell number of the human $\mathrm{SCN}$ in relation to the variations in photoperiod; values were twice as high in autumn as in summer [22]. Similar circadian fluctuations were observed in the SCN of young 
adults (Hofman and Swaab, unpubl. results). A lesion in the suprachiasmatic region of the anterior hypothalamus, e. g. as the result of a tumor, indeed results in disturbed circadian rhythmus in humans $[53,7]$. Totally blind people may show free-running temperature, cortisol and melatonin rhythms. In addition, they may suffer from sleep disturbances [47]. These observations underscore the importance of the light-dark cycle for synchronisation and of the SCN for circadian rhythms in humans.

Recent morphometric analysis of the SCN in 10 homosexual men revealed that the volume of this nucleus was 1.7 times as large as that of a reference group of 18 male subjects, and that it contained 2.1 times as many cells [62]. It might be that programmed postnatal cell death, usually occurring from 13-16 months after birth onwards, is limited in homosexual men. In 3 male to female transsexuals extreme values were observed in the SCN and SDN. It is not yet clear what the functional implications of this findings might be, although there are various indications that the SCN is involved in aspects of sexual behavior and reproduction [59].

Age-related changes in circadian rhythms have been reported in humans as well as in non-human species [71]. A fragmentation of sleep-wake patterns occurs in senescence, a phenomenon that is even more pronounced in Alzheimer's disease $[37,75,42]$. In Alzheimer's disease the disruptions of the circadian rhythms are often so severe that they lead to hospitalization of the elderly [49] and are even thought to contribute to mental decline [11]. For this reason the number of cells in the SCN was determined during aging and in Alzheimer's disease. A marked decrease was found in SCN total cell number and in the number of vasopressin-expressing neurons in subjects of $80-100$ years of age, while in Alzheimer's disease these changes were even more dramatic [58, 58] Cytoskeletal alterations have also been found in the SCN of Alzheimer patients [64]. With respect to the degenerative changes of the SCN it may be important to note that both the retina and the optic nerve, which provide direct and indirect light input to the SCN, show degenerative changes in Alzheimer's disease [19, $65,28]$. In addition to degenerative changes, Alzheimer patients are generally exposed to less light than their age-matched controls [5]. As a result, both the input of the visual system to the SCN and the SCN itself seem to be seriously affected in Alzheimer's disease. The contribution of each of these components to circadian disturbances has yet to be investigated. Preliminary observations [40] show that behavioral disorders such as wandering, agitation or delirium almost disappeared, and that sleep-wake rhythm disorders improved in Alzheimer patients following exposure to bright light for two hours per morning. This indicates that stimulation of the SCN might have important therapeutic consequences. 


\section{Sexually dimorphic nucleus (intermediate nucleus, INAH-1)}

The sexually dimorphic nucleus of the preoptic area (SDN) was first described in the rat brain by Gorski et al. [16]. Due to differences in perinatal steroid levels, the SDN in the male rat is $3-8$ times larger than in the female rat [27]. On the basis of lesion experiments in rats, it was found that the SDN seems to be involved in aspects of male sexual behavior, i. e. mounting, intro-mission and ejaculation $[66,8]$. However, the effects of lesions on sexual behavior are only slight, so it may well be that the major functions of the SDN are still unknown at present.

The SDN in the young adult human brain is twice as large in males $\left(0.20 \mathrm{~mm}^{3}\right)$ as in females $\left(0.10 \mathrm{~mm}^{3}\right)$ and contains twice as many cells [57]. The SDN is located between the supraoptic and paraventricular nucleus at the same rostrocaudal level as the suprachiasmatic nucleus. The SDN is identical to the "intermediate nucleus" described by Braak and Braak [3], and to the INAH-1 of Allen et al. [2]. In the human brain, sexual dimorphism is not present at birth. At that moment, cell numbers are similar in boys and girls and the SDN contains no more than $20 \%$ of the number of cells found around $2-4$ years of age. From birth up to this age, cell numbers increase equally rapidly in both sexes. A sex difference does not occur until about the fourth year postnatally, when cell numbers start to decrease in girls, whereas in males they remain stable until approximately 50 years of age, when they rapidly decrease. In females a second phase of marked cell loss sets in after the age of 70 (Fig. 1) $[60,20]$. The sharp decrease in cell numbers in the SDN later in life might be related to the dramatic hormonal changes which accompany both male and female senescence [20], and to the decrease in male sexual activity [72]. It is not clear whether the hormonal changes are cause or effect of the observed cell loss in this nucleus. Cell numbers in the SDN of Alzheimer's disease patients were found to be within the normal range for age and sex [60].

A prominent theory is that sexual orientation develops as a result of an interaction between the developing brain and sex hormones [10, 15]. According to Dörner's hypothesis, male homosexuals have a female differentiation of the hypothalamus. This theory was not supported by our data on the SDN in homosexual men. Neither the SDN volume nor the cell numbers of homosexual men who died of AIDS differed from that of the male reference groups in the same age range, nor from that of heterosexuals also suffering from AIDS [60, 62]. The fact that no difference in SDN cell number was observed between homo- and heterosexual men who had died of AIDS refutes the general formulation of Dörner's hypothesis that male homosexuals have "a female hypothalamus". 


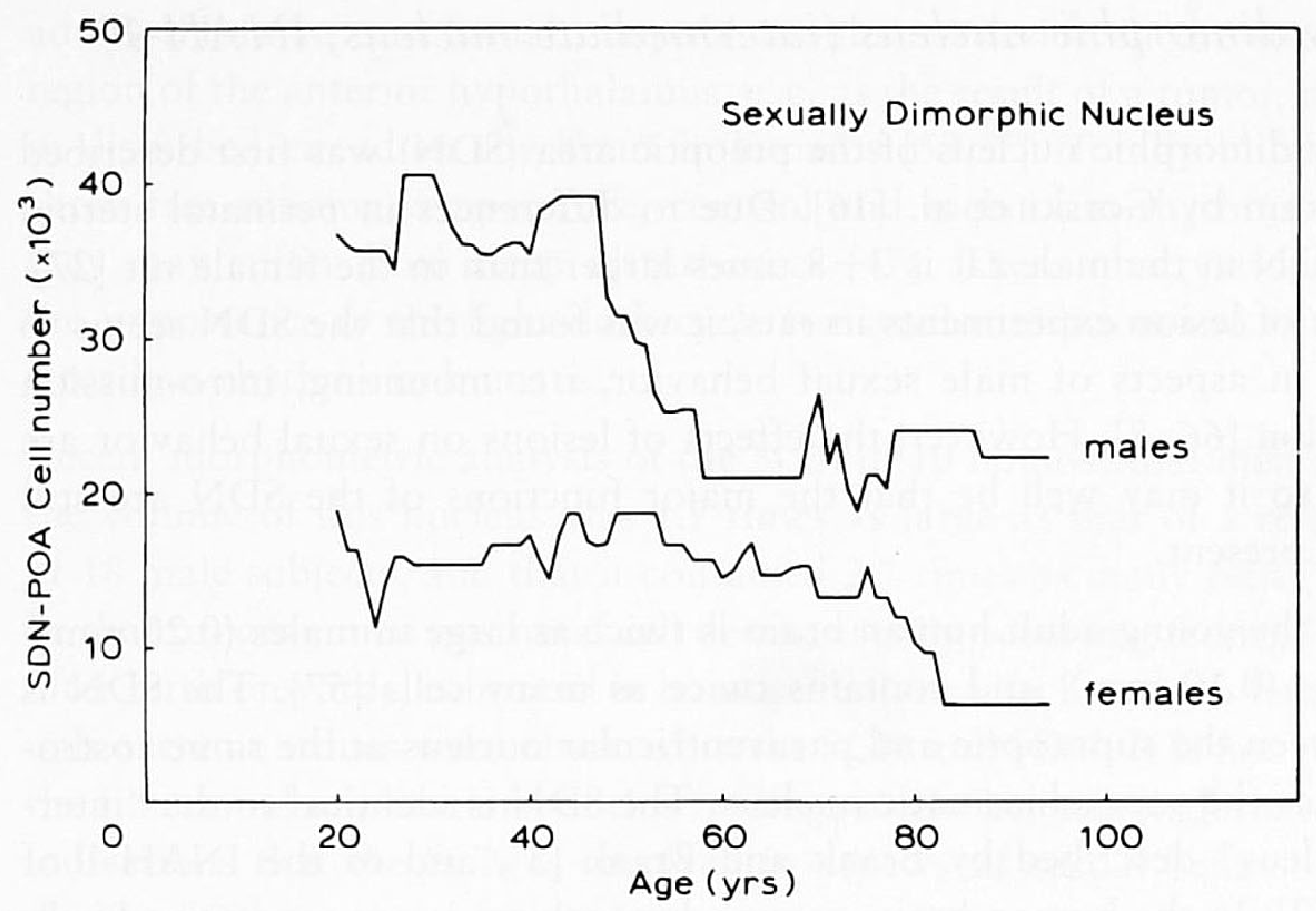

Fig. 1 Age-related changes in the total cell number of the sexually dimorphic nucleus of the preoptic area (SDN-POA) in the human hypothalamus. The general trend in the data is enhanced by using smoothed growth curves. Note that in males SDN-POA cell number steeply declines between the age of 50-60 years, whereas in females a more gradual cell loss is observed around the age of 80 years. These curves demonstrate that the reduction in cell number in the human SDN-POA in senescence is a non-linear, sex-dependent process. (From Hofman and Swaab, 1989, with permission.)

In Alzheimer's disease - not in controls - SDN neurons and dystrophic neurites are stained with cytoskeletal markers such as Alz-50, anti-tau, anti-paried helical filaments and anti-ubiquitin, in spite of the fact that there is no difference in SDN cell numbers between Alzheimer patients and controls [64].

\section{Supraoptic and paraventricular nucleus and accessory nuclei}

The large neurosecretory cells of the hypothalamic supraoptic and paraventricular nucleus (SON and PVN) produce the neuropeptides vasopressin and oxytocin which are released into the blood circulation in the neurohypophysis. Vasopressin acts as an anti-diuretic hormone on the kidney and in women oxytocin is involved in labor and lactation. Parvocellular vasopressin neurons of the PVN project into the brain and influence central processes [14]. Oxytocin has central effects for example food intake (see below), maternal and reproductive behavior [25] and in males might be involved in sexual arousal and ejaculation [39].

The neurons of the SON and PVN form a population of extremely stable cells in normal aging and in Alzheimer's disease; no loss in neurons or total cell 


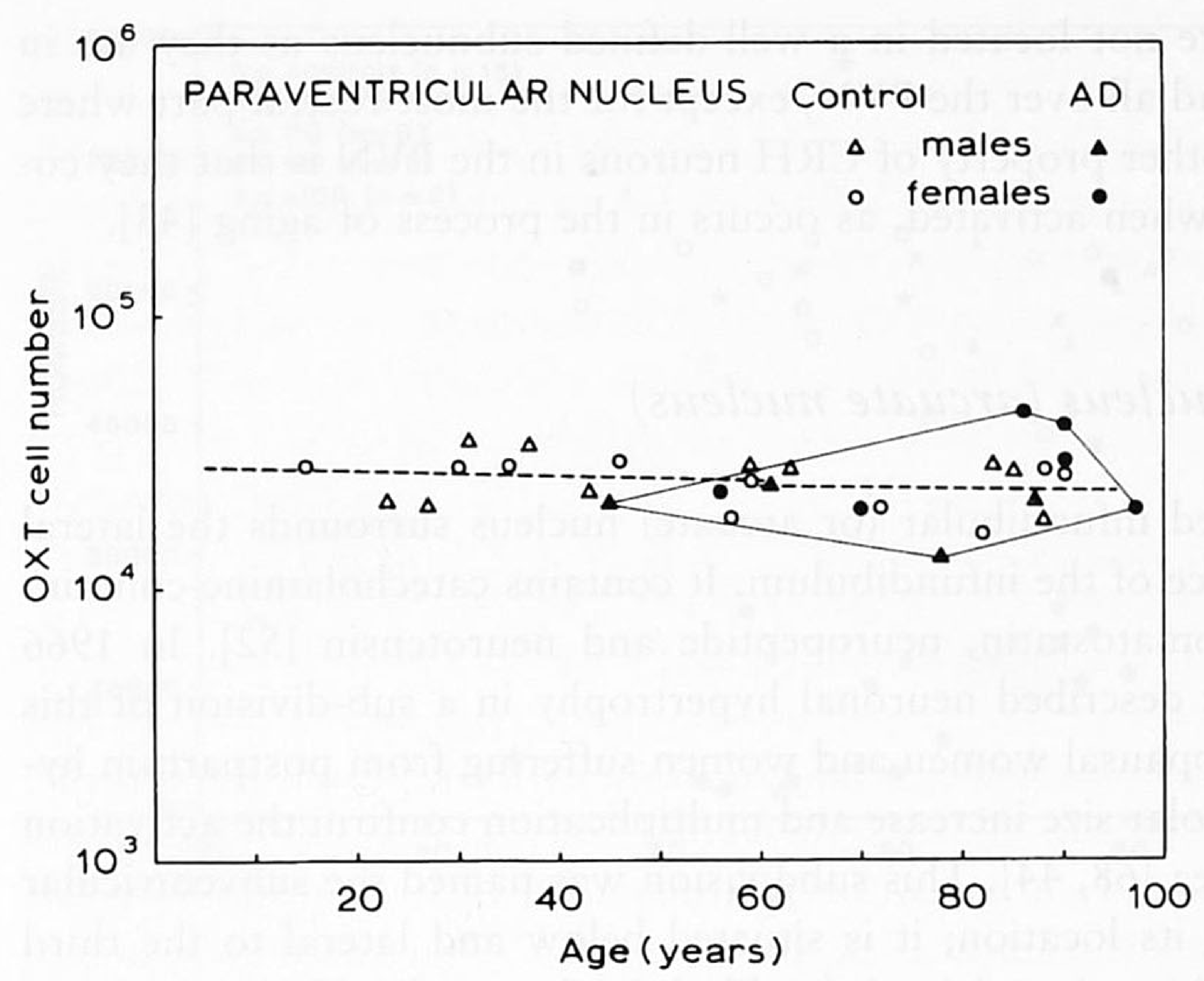

Fig. 2 Linear regression between OXT cell number in the PVN and age. Data of male and female control patients did not differ and were pooled. No statistically significant correlations were observed in either young or old control subjects. Values of male and female AD patients are delineated by a minimum convex polygon and were within the range of the controls. (From Wierda et al., 1991, with permission.)

number was observed (Fig. 2) $[21,18,74,70]$. The observation that no cytoskeletal alterations were found in Alzheimer patients with several anti-bodies in the SON [64] is in accordance with this stability. Although in the PVN of Alzheimer patients some neuronal and dystrophic neurite staining is observed with cytoskeletal antibodies [64], the cell number in the PVN remains the same. Various observations provide evidence for the hypothesis that activation of neurons may interfere with the process of aging, and thus prolong the lifespan of neurons or restore their function. This hypothesis is paraphrased as 'use it or lose it' [63]. The SON and PVN neurons are not only metabolically highly active throughout life, but are extra activated in senescence as well, as can be judged from the increase in the size of the vasopressin-containing perikarya [13], nucleoli [23] and Golgi apparatus [35], and the enhanced plasma levels of vasopressin (Frolkis et al., 1982) and neurophysins [34]. Similar activation of vasopressin neurons was observed in the aged rat $[12,17]$ and is probably due to a loss of vasopressin receptors in the kidneys during aging [45].

In contrast to the SON, the PVN does not only contain magnocellular vasopressin and oxytocin neurons, but also parvicellular ones that project to central brain regions (see above) or to the median eminence. Examples of the latter type of neurons are the corticotropin-releasing hormone $(\mathrm{CRH})$ neurons. In the 
human PVN they are not located in a well-defined subnucleus as they are in the rat, but are spread all over the PVN, except for the most rostral part where they are absent. Another property of CRH neurons in the PVN is that they coexpress vasopressin when activated, as occurs in the process of aging [43].

\section{Infundibular nucleus (arcuate nucleus)}

The horseshoe-shaped infundibular (or arcuate) nucleus surrounds the lateral and posterior entrance of the infundibulum. It contains catecholamine-containing neurons [55], somatostatin, neuropeptide and neurotensin [52]. In 1966 Sheehan and Kovacs described neuronal hypertrophy in a sub-division of this nucleus in post-menopausal women and women suffering from postpartum hypopituitarism. Nucleolar size increase and multiplication confirm the activation of neurons in this area $[68,44]$. This subdivision was named the subventricular nucleus, referring to its location; it is situated below and lateral to the third ventricle, and caudally to the tubero-infundibular sulcus. Infundibular neuronal hypertrophy has also been described in chronically ill, hypogonadal men and in patients suffering from starvation and gonadal atrophy [67], (for review see [44]). The hypertrophied neurons contain increased amounts of neurokinin B (NKB), substance P and estrogen receptor transcripts. LHRH neurons are also found in this nucleus, but the hypertrophied neurons themselves do not contain this peptide. The NKB-containing neurons probably participate in the hypothalamic circuitry, which regulates estrogen negative feedback on gonadotropin release in humans by acting as an interneuron on the LHRH-containing cells. In addition, the NKB neurons may be involved in the initiation of menopausal flushes [44].

\section{Lateral tuberal nucleus}

The lateral tuberal nucleus (nucleus tuberalis lateralis, NTL) is present in humans and higher primates. Macroscopically, the presence of the NTL is revealed by the "lateral eminence on the ventral surface of the tuber cinerium" [33]. The neurotransmitter content of the NTL and the connections with other parts of the brain are as yet unknown, but receptors for corticotropin-releasing factor, somatostatin, muscarinic cholinergic receptors, benzodiazepin receptors and $\mathrm{N}$ methyl-D-aspartate (NMDA) receptors have been localized in the NTL [32]. In adulthood the NTL contains some 60,000 neurons, whereas in Huntington's disease this number may be reduced to less than 10,000 (Fig. 3), and gliosis is found depending on the age at onset of the disease as well as the age at death 


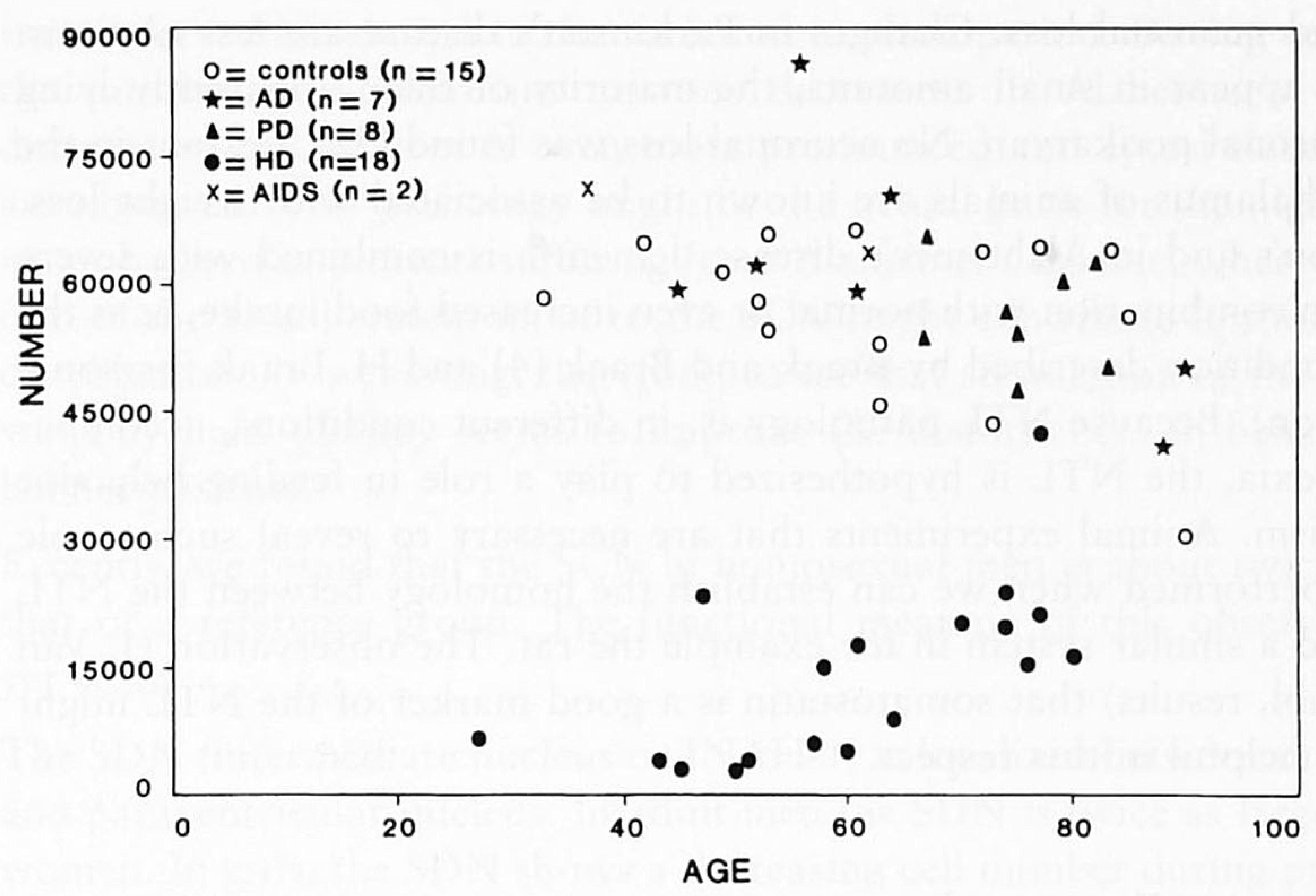

Fig. 3 Neuron number counts of the NTL in normal controls and neurological diseases. AD, Alzheimer's disease; PD, Parkinson's disease; HD, Huntington's disease; AIDS: acquired immunodeficiency syndrome. Linear regression analysis of neuronal numbers vs. age: for controls only $(\mathrm{n}=15)$ : neuron number $=71955-($ age 237.92$), \mathrm{r}=-0.38, \mathrm{P}=0.15$; for the total group of controls, AD, PD and AIDS $(n=32)$ : neuron number $=79126-($ age 315.19$), r=-0.48$, $\mathrm{P}=0.0053$. (From Kremer, 1992, with permission.)

[30]. Neuronal loss in the NTL may be a good marker of the severity of the disease, and the NTL may be one of the brain structures that is primarily affected by the Huntington's disease gene [32]. It is presumed that this NTL vulnerability is related to the high amount of NMDA receptors in this nucleus. Pathological changes in the NTL have also been described in depression [24], Kallman's syndrome [29] and dementia with intracranial argyrophilic grains and silver-staining coiled bodies containing straight filaments [4]. In Alzheimer's disease, the number of NTL neurons did not differ from that in controls. The number of plaques in this nucleus was low, and they were exclusively of the amorphous type. Neurofibrillary tangles were rare in conventional silver stainings. Yet immunocytochemical staining, using the monoclonal antibody Alz-50, showed such an abundant reactivity of both perikarya and neurites that the NTL of Alzheimer's disease patients could even be recognized by the naked eye [31]. Staining of Alzheimer hypothalami with anti-tau 1, anti-paired helical filaments and anti-ubiquitin showed about the same density of NTL neurons but far less neuritic staining [64]. The Alzheimer pattern of Alz-50 staining was also encountered in patients with Down's syndrome [32]. The NTL seems to represent a brain area in which Alzheimer's disease affects the neurons in a limited way, without further progress to the classical changes of silver-staining 
of tangles and neuronal loss. Changes in Parkinson's disease are less obvious: Lewy bodies appear in small amounts, the majority of them apparently lying outside a neuronal perikaryan. No neuronal loss was found [32]. Lesions in the lateral hypothalamus of animals are known to be associated with weight loss. In Huntington's and in Alzheimer's disease dementia is combined with severe weight-loss in combination with normal or even increased food intake, as is the case in the condition described by Braak and Braak [4] and H. Braak (personal communication). Because NTL pathology is, in different conditions, accompanied by cachexia, the NTL is hypothesized to play a role in feeding behavior and metabolism. Animal experiments that are necessary to reveal such a role can only be performed when we can establish the homology between the NTL in human and a similar system in for example the rat. The observation ( $\mathrm{J}$. Van de Nes, unpubl. results) that somatostatin is a good marker of the NTL might be extremely helpful in this respect.

\section{Tuberomammillary nucleus}

The tuberomammillary nucleus (TM) is formed by large, irregularly bordered, darkly staining neurons that surround the NTL, the fornix in its final descending course, and the mammillary body [9]. Many of its neurons project extensively to the cortex [50]. For example, the major, if not the sole, histaminergic cortical innervation in rodents $[56,73]$ as well as in man $[1,41]$ originates from this group. For a long time now TM has been known to be affected by Alzheimer's disease: the occurrence of tangles and deposits of plaques can be found in this nucleus $[26,51,54,69)$. In the TM of Alzheimer patients we found numerous Alz-50 staining neurites. Neuritic staining with other cytoskeletal antibodies was markedly less than in NTL. In contrast to the NTL, the TM did show neurofibrillary tangles in Palmgren's silver impregnation [64]. In addition, Lewy body formation has been observed in the TM in Parkinson's disease [48]. Morphometrics have only been applied to a few subjects and concern Galanin neurons. Their number did not change in Alzheimer's or Parkinson's disease [6]. No clear qualitative changes in the number of histamine neurons were observed between Alzheimer patients and controls [6]. Although the NTL is seriously affected in Huntington's disease (see above) the surrounding neurons of the TM are not affected in this condition. Interestingly, contrary to the NTL, the TM does not contain NMDA receptors.

\section{Summary and conclusions}

The SCN coordinates circadian and circannual rhythms. A marked seasonal and circadian variation in the volume and vasopressin cell number of the SCN 
was observed in relation to the variation in photoperiod. During normal aging, the number of vasopressin neurons decreases. In Alzheimer's disease, the decrease in cell number is even more pronounced and cytoskeletal alterations are observed. This pathology might be the neural basis for the nightly restlessness observed in patients suffering from Alzheimer's disease, whereas degeneration of the visual system input to the SCN might contribute to these functional disturbances. It is exciting, therefore, to see that stimulation of the visual pathways by light therapy seems to improve the disturbances in behavior in $\mathrm{Alz}$ heimer patients.

Recently, we found that the SCN in homosexual men is about twice as large as that of a reference group. The functional meaning of this observation is not yet clear.

The SDN (intermediate nucleus or INAH-1) is localized between the supraoptic and paraventricular nucleus. In adult men the SDN is twice as large as in adult women. In girls, the SDN shows a decreasing cell number during pre-pubescent development, leading to sexual dimorphism. During aging a decrease in cell number is found in both sexes. The latter change may be related to a decrease in sexual activity and to changes in hormone levels. In Alzheimer's disease cytoskeletal changes are found in the SDN, but SDN celi numbers decrease at a similar rate as in normal aging. Since the SDN in homo- and heterosexual men is similar in size and cell number, the hypothesis that homosexual men have a female hypothalamus is not supported.

The cells of the SON and PVN produce vasopressin or oxytocin. These nuclei are examples of neuron populations that seem to stay perfectly intact in aging and Alzheimer's disease. The cells do not show cytoskeletal changes in Alzheimer's disease. We hypothesize that this might be due to the activation of these neuroendocrine cells during the aging process. On the other hand, in other conditions the PVN may be affected, since the oxytocin neuron number is $50 \%$ lower in Prader-Willi syndrome, 40\% lower in AIDS and 20\% lower in Parkinson's disease.

Parvicellular corticotropin-releasing hormone (CRH)-containing neurons are found throughout the PVN. CRH neurons are activated in the course of aging as appears from the increasing proportion of neurons showing co-localization with vasopressin.

The subventricular nucleus contains hypertrophic neurons in postmenopausal women, in hypogonadal men, and in conditions such as starvation and postpartum hypopituitarism. The hypertrophied neurons contain neurokinin-B (NKB), substance-P and estrogen receptors and probably act on LHRH neurons as interneurons. The NKB neurons may also be involved in the initiation of menopausal flushes. 
The NTL and TM are lateral structures of the tuberal region. The NTL might be involved in feeding behavior and metabolism. In Huntington's disease the majority of NTL neurons are lost. Although it does not show any decrease in neuronal numbers in Alzheimer's disease, a very strong Alz-50 staining is present in the NTL of Alzheimer patients, which is due to a dense network of dystrophic neurites and numerous staining perikarya. The NTL in Alzheimer's disease patients seems, therefore, to be in an early phase of the disease process. In addition, we may conclude that Alz-50 is not simply a marker for impending cell death. In Parkinson's disease only a few Lewy bodies are found, and no cell loss is observed.

Tuberomammillary nucleus (TM) neurons project to the cortex. Neurons contain histamine or galanin. Their number does not seem to diminish in Alzheimer's disease, although TM neurons show cytoskeletal alterations, plaques and tangles. In addition, Lewy bodies have been observed in the TM of Parkinson patients.

It can be concluded that the various hypothalamic nuclei are involved in a great number of functions and show clear and differential changes in development with respect to sex, in menopause, in aging and in a number of neurological diseases. We believe that only a small proportion of such changes have, at present, been identified.

\section{Acknowledgements}

Brain material was obtained from the Netherlands Brain Bank, Amsterdam (coordinator Dr. R. Ravid). The authors would like to express their thanks to Ms. W. Verweij for her secretarial help, and Mr. G. Van der Meulen for his photographic work. As part of the AMSTEL project, part of this study was supported by the Stimuleringsprogramma Gezondheidsonderzoek (SGO) of the Netherlands Ministry of Science and Education. Financial support was also obtained from Mrs. E. J. M. Stevens.

\section{References}

[1] Airaksinen, M. S., A. Paer, L. Paljärvi et al.: Histamine neurons in human hypothalamus: anatomy in normal and Alzheimer diseased brains. Neurosci. 44 (1991) 465-481.

[2] Allen, L. S., M. Hines, J. E. Shryne et al.: Sex difference in the bed nucleus of the stria terminalis of the human brain. J. Comp. Neurol. 302 (1989) 697-706.

[3] Braak, H., E. Braak: The hypothalamus of the human adult: chiasmatic region. Anat. Embryol. 176 (1987) 315-330. 
[4] Braak, H., E. Braak: Cortical and subcortical argyrophylic grains characterize a disease associated with adult onset dementia. Neuropathol. Appl. Neurobiol. 15 (1989) 13-26.

[5] Campbell, S. S., D. F. Kripke, J. C. Gillin et al.: Exposure to light in healthy elderly subjects and Alzheimer patients. Physiol. Behav. 42 (1988) 141-144.

[6] Chan-Palay, V. L., B. Jentsch: Galinin tuberomammillary neurons in the hypothalamus in Alzheimer's and Parkinson's disease. In: D. F. Swaab, M. A. Hofman, M. Mirmiran et al. (eds.): The Human Hypothalamus in Health and Disease. Progress in Brain Research vol. 93, pp. 263-270, Elsevier, Amsterdam 1992.

[7] Cohen, R. A. and H. E. Albers: Disruption of human circadian and cognitive regulation following a discrete hypothalamic lesion: a case study. Neurology 41 (1991) 726-729.

[8] De Jonge, F. H., A. L. Louwerse, M. P. Ooms et al.: Lesions of the SDN-POA inhibit sexual behaviour of male Wistar rats. Brain Res. Bull. 23 (1989) 483-492.

[9] Diepen, R.: Der Hypothalamus. In: W. Bargmann (ed.) Handbuch der mikroskopischen Anatomie des Menschen IV/7, pp. 1-181, Springer, Berlin 1962.

[10] Dörner, G.: Neuroendocrine response to estrogen and brain differentiation in heterosexuals, homosexuals, and transsexuals. Arch. Sexual Behav. 17 (1988) 57-75.

[11] Fekete, M., J. M. Van Ree, R. J. M. Niesink et al.: Disruption of circadian rhythms induces retrograde amnesia. Physiol. Behav. 34 (1985) 883-887.

[12] Fliers, E., D. F. Swaab: Activation of vasopressinergic and oxytocinergic neurons during aging in the Wistar rat. Peptides 4 (1983) 165-170.

[13] Fliers, E., G. J. De Vries, D. F. Swaab: Changes with aging in the vasopressin and oxytocin innervation of the rat brain. Brain Res. 348 (1985) 1-8.

[14] Fliers, E., S. E. F. Guldenaar, N. Van de Wal et al.: Extrahypothalamic vasopressin and oxytocin in the human brain; presence of vasopressin cells in the bed nucleus of the stria terminalis. Brain Res. 375 (1986) 363-367.

[15] Gladue, B. A., R. Green, R. E. Helleman: Neuroendocrine response to estrogen and sexual orientation. Science 225 (1984) 1496-1499.

[16] Gorski, R. A., J. H. Gordon, J. E. Shryne: Evidence for a morphological sex difference whithin the medial preoptic area of the rat brain. Brain Res. 148 (1978) 333-346.

[17] Goudsmit, E., E. Fliers, D. F. Swaab: Vasopressin and oxytocin excretion in the Brown Norway rat in relation to aging, water metabolism and testosterone. Mech. of Ageing and Development 44 (1988) 241-252.

[18] Goudsmit, E., M. A. Hofman, E. Fliers et al.: The supraoptic and paraventricular nuclei of the human hypothalamus in relation to sex, age and Alzheimer's disease. Neurobiol. Aging 11 (1990) 529-536.

[19] Hinton, D. R., A. A. Sadun, J. C. Blanks et al.: Optic nerve degeneration in Alzheimer's disease. N. Engl. J. Med. 315 (1986) 485-487.

[20] Hofman, M. A., D. F. Swaab: The sexually dimorphic nucleus of the preoptic area in the human brain: a comparative morphometric study. J. Anat. 164 (1989) 55-72.

[21] Hofman, M. A., E. Goudsmit, J. S. Purba et al.: Morphometric analysis of the supraoptic nucleus in the human brain. J. Anat. 172 (1990) 259-270.

[22] Hofman, M. A., D. F. Swaab: Seasonal changes in the suprachiasmatic nucleus of man. Neurosci. Lett. 139 (1992) 257-260.

[23] Hoogendijk, J. E., E. Fliers, D. F. Swaab et al.: Activation of vasopressin neurons in the human supraoptic and paraventricular nucleus in senescence and senile dementia. J. Neurol. Sci. 69 (1985) 291-299.

[24] Horn, E., B. Lach, Y. Lapierre et al.: Hypothalamic pathology in the neuroleptic malignant syndrome. Am. J. Psychiatry 145 (1988) 617-620.

[25] Insel, T. R.: Oxytocin - a neuropeptide for affiliation: evidence from behavioral, receptor autoradiographic, and comparative studies. Psychoneuroendocrinology 17 (1992) 3-35. 
[26] Ishii, T.: Distribution of Alzheimer's neurofibrillary changes in the brain stem and hypothalamus of senile dementia. Acta Heuropathol. 6 (1966) 181-187.

[27] Jacobson, C. D., J. E. Shryne, F. Shapiro et al.: Ontogeny of the sexually dimorphic nucleus of the preoptic area. J. Comp. Neurol. 193 (1980) 541-548.

[28] Katz, B., S. Rimmer, V. Iragui et al.: Abnormal pattern electroretinogram in Alzheimer's disease: evidence for retinal ganglion cell degeneration? Ann. Neurol. 26 (1989) 221-225.

[29] Kovacs, K., H. L. Sheehan: Pituitary changes in Kallman's syndrome. A histologic, immunocytologic, ultrastructural, and immunoelectron microscopic study. Fert. Steril. 37 (1982) 83-89.

[30] Kremer, H. P. H., R. A. C. Roos, G. Dingjan et al.: Atrophy of the hypothalamic lateral tuberal nucleus in Huntington's disease. J. Neuropathol. Exp. Neurol. 49 (1990) 371-382.

[31] Kremer, H. P. H., D. F. Swaab, G. Th. A. M. Bots et al.: The hypothalamic lateral tuberal nucleus in Alzheimer's disease. Ann. Neurol. 29 (1991) 279-284.

[32] Kremer, H. P. H.: The hypothalamic lateral tuberal nucleus: normal anatomy and changes in neurological diseases. In: D. F. Swaab, M. A. Hofman, M. Mirmiran et al. (eds.): The Human Hypothalamus in Health and Disease, Progress in Brain Research vol. 93, pp. 249-261, Elsevier, Amsterdam 1992.

[33] Le Gros Clark, W. E.: Morphological aspects of the hypothalamus. In: W. E. Le Gros Clark, J. Beattie, G. Riddoch et al. (eds.) The Hypothalamus. Morphological, Functional, Clinical and Surgical Aspects, pp. 1-68, Oliver and Boyd, Edinburgh 1938.

[34] Legros, J. J., P. Gilot, S. Schmitz et al.: Neurohypophyseal peptides and cognitive function: a clinical approach. In: F. Brambilla, G. Racagni, D. de Wied (eds.) Progress in Psychoneuroendocrinology, pp. 325-337, Elsevier Science Publishers, Amsterdam 1980.

[35] Lucassen, P. J., D. F. Swaab, R. Ravid et al.: Activation of the Golgi-apparatus in human supraoptic and paraventricular neurons with aging and in Alzheimer's disease (1993, in prep.).

[36] Mai, J. K., O. Kedziora, L. Teckhaus et al.: Evidence for subdivisions in the human suprachiasmatic nucleus. J. Comp. Neurol. 305 (1991) 508-525.

[37] Mirmiran, M., J. Overdijk, W. Witting et al.: A simple method for recording and analyzing circadian rhythms in man. J. Neurosci. Meth. 25 (1988) 209-214.

[38] Moore, R. Y.: The organization of the human circadian timing system. In: D. F. Swaab, M. A. Hofman, M. Mirmiran et al. (eds.) The Human Hypothalamus in Health and Disease, Progress in Brain Research vol. 93, pp. 99-117, Elsevier, Amsterdam 1992.

[39] Murphy, M. R., J. R. Seckl, S. Burton et al.: Changes in oxytocin and vasopressin secretion during sexual activity in men. J. Clin. Endocrin. Metab. 65 (1987) 738-741.

[40] Okawa, M., Y. Hishikawa, S. Hozumi et al.: Sleep-wake rhythm disorder and phototherapy in elderly patients with dementia. In: G. Racagni et al. (eds.) Biological Psychiatry 1 (1991) $837-840$.

[41] Panula, P., M. S. Airaksinen, U. Pirvola et al.: Histamine containing neuronal system in human brain. Neuroscience 34 (1990) 129-132.

[42] Prinz, P. N., P. P. Viatliano, M. V. Vitiello et al.: Sleep, EEG and mental function changes in senile sementia of the Alzheimer's type. Neurobiol. Aging 3 (1982) 361-370.

[43] Raadsheer, F. C., A. A. Sluiter, R. Ravid et al.: Localization of corticotropin-releasing hormone (CRH) neurons in the paraventricular nucleus of the human hypothalamus; age-dependent colocalization with vasopressin. 615 (1993, pp. 50-62).

[44] Rance, N. E.: Hormonal influences on morphology and neuropeptide gene expression in the infundibular nucleus of post-menopausal women. In: D. F. Swaab, M. A. Hofman, M. Mirmiran et al. (eds.) The Human Hypothalamus in Health and Disease, Progress in Brain Research vol. 93, pp. 221-236, Elsevier, Amsterdam 1992.

[45] Ravid, R., E. Fliers, D. F. Swaab et al.: Changes in vasopressin and testosterone in the senescent Brown-Norway (BN/BiRij) rat. Gerontology 33 (1987) 87-98. 
[46] Rusak, B., I. Zucker: Neural regulation of circadian rhythms. Physiol. Rev. 59 (1979) 449526.

[47] Sack, R. L., A. J. Lewy, M. L. Blood et al.: Circadian Rhythm Abnormalities in totally blind people: incidence and clinical significance. J. Clin. Endocrin. Metab. 75 (1992) 127-134.

[48] Sandyk, R., R. P. Iacono, C. R. Bamford: The hypothalamus in Parkinson's disease. Ital. J. Neurol. Sci. 8(3) (1987) 227-234.

[49] Sanford, J. R. A.: Tolerance of debility in elderly dependents by supporters at home: its significance for hospital practice. Br. Med. J. 3 (1975) 471-473.

[50] Saper, C. B.: Organization of cerebral cortical afferent systems in the rat. II Hypothalamocortical projections. J. Comp. Neurol. 237 (1985) 21-46.

[51] Saper, C. B., D. C. German: Hypothalamic pathology in Alzheimer's disease. Neurosci. Lett. 74 (1987) 364-370.

[52] Saper, C. B.: Hypothalamus. In: G. Paxinos (ed.): The Human Nervous System, pp. 389-413, Academic Press, San Diego 1990.

[53] Schwartz, W. J., N. A. Bosis, E. T. Hedley-Whyte: A discrete lesion of ventral hypothalamus and optic chiasm that disturbed the daily temperature rhythm. J. Neurol. 233 (1986) 1-4.

[54] Simpson, W. A., C. M. Yates, A. G. Watts et al.: Congo red birefringent structures in the hypothalamus in senile dementia of the Alzheimer type. Neuropathol. Appl. Neurobiol. 14 (1988) 381-393.

[55] Spencer, S., C. B. Saper, T. Joh et al.: Distribution of catecholamine-containing neurons in the normal human hypothalamus. Brain Res. 328 (1985) 73-80.

[56] Steinbusch, H. W. M., A. H. Mulder: Localization and projections of histamine immunoreactive neurons in the central nervous system of the rat. In: A. Björklund, T. Hökfelt, M. J. Kuhar (eds.): Handbook of Chemical Neuroanatomy 3, pp. 126-140, Elsevier, Amsterdam 1984.

[57] Swaab, D. F., E. Fliers: A sexually dimorphic nucleus in the human brain. Science 228 (1985) $1112-1115$.

[58] Swaab, D. F., E. Fliers, T. S. Partiman: The suprachiasmatic nucleus of the human brain in relation to sex, age and senile dementia. Brain Res. 342 (1985) 37-44.

[59] Swaab, D. F., B. Roozendaal, R. Ravid: Suprachiasmatic nucleus in aging, Alzheimer's disease, transsexuality and Prader-Willi syndrome. In: E. R. De Kloet, V. M. Wiegant, D. De Wied (eds.): Neuropeptides and Brain Function, Progress in Brain Research vol. 72, pp. 301-310, Elsevier, Amsterdam 1987.

[60] Swaab, D. F., M. A. Hofman: Sexual differentiation of the human hypothalamus: ontogeny of the sexually dimorphic nucleus of the preoptic area. Dev. Brain Res. 44 (1988) 314-318.

[61] Swaab, D. F., M. A. Hofman, M. B. O. M. Honnebier: Development of vasopressin neurons in the human suprachiasmatic nucleus in relation to birth. Dev. Brain Res. 52 (1990) 289-293.

[62] Swaab, D. F., M. A. Hofman: An enlarged suprachiasmatic nucleus in homosexual men. Brain Res. 537 (1990) 141-148.

[63] Swaab, D. F.: Brain aging and Alzheimer's disease: "wear and tear" versus "use it or lose it". Neurobiol. Aging 12 (1991) 317-324.

[64] Swaab, D. F., I. Grundke-Iqbal, K. Iqbal et al.: Tau and ubiquitin in the human hypothalamus in aging and Alzheimer's disease. Brain Res. 590 [1992) 239-249.

[65] Trick, G. L., M. C. Barris, M. Bickler-Bluth: Abnormal pattern electroretinograms in patients with senile dementia of the Alzeimer type. Ann. Neurol. 26 (1989) 226-231.

[66] Turkenburg, J. L., D. F. Swaab, E. Endert et al.: Effects of lesions of the sexually dimorphic nucleus on sexual behaviour of testosterone-treated female Wistar rats. Brain Res. Bull. 21 (1988) 215-224.

[67] Ule, G., C. Walter: Morphological feedback effect on the nucleoli of the neurons in the nucleus arcuatus (infundibularis) to hypophyseal hypogonadism in juvenile haemochromatosis. Acta Neuropathol. 61 (1983) 81-84. 
[68] Ule, G., K. Schwechheimer, C. Tschahargane: Morphological feedback effect on neurons of the nucl. arcuatus (sive infundibularis) and nucl. subventricularis hypothalami due to gonadal atrophy. Virchows Arch. 400 (1983) 297-308.

[69] Ulfig, N., H. Braak: Amyloid deposits and neurofibrillary changes in the hypothalamic tuberomammillary nucleus. J. Neural. Transm. (P. D. Sect) 1 (1984) 143.

[70] Van der Woude, P. F., E. Goudsmit, M. Wierda et al.: Increase in the number of vasopressin immunoreactive cells in the human paraventricular nucleus with normal aging, but not in Alzheimer's disease (1993, in prep.).

[71] Van Gool, W. A., M. Mirmiran: Aging and circadian rhythms. In: Swaab, D. F. et al. (eds.) Aging of the Brain and Alzheimer's Disease, Progress in Brain Research vol. 70, pp. 255-279, Elsevier, Amsterdam 1986.

[72] Vermeulen, A.: Androgens and male senescence. In: E. Nieschlag, H. M. Behre (eds.) Testosterone, Action Deficiency Substitution. pp. 261-276, Springer Verlag, Berlin 1990.

[73] Watanabe, T., Y. Taguchi, S. Shiosaka et al.: Distribution of the histaminergic neuron system in the central nervous system of rats: a fluorescent immunohistochemical analysis with histidine decarboxylase as a marker. Brain Res. 295 (1984) 13-25.

[74] Wierda, M., E. Goudsmit, P. F. Van der Woude et al.: Oxytocin cell number in the human paraventricular nucleus remains constant with aging and in Alzheimer's disease. Neurobiol. Aging 12 (1991) 511-516.

[75] Witting, W., I. H. Kwa, P. Eikelenboom et al.: Alterations in the circadian rest-activity rhythm in aging and Alzheimer's disease. Biol. Psychiatry 27 (1990) 563-572. 